EVIDENCE BASED PUBLIC HEALTH POLICY AND PRACTICE

\title{
Do social and economic reforms change socioeconomic inequalities in child mortality? A case study: New Zealand 1981-1999
}

\author{
Caroline Shaw, Tony Blakely, June Atkinson, Peter Crampton
}

J Epidemiol Community Health 2005;59:638-644. doi: 10.1136/jech.2004.032466

See end of article for
authors' affiliations
$\ldots \ldots \ldots \ldots \ldots \ldots \ldots \ldots$
Correspondence to:
Dr T Blakely, Department
of Public Health,
Wellington School of
Medicine and Health
Sciences, University of
Otago, PO Box 7343,
Wellington, New Zealand;
tblakely@wnmeds.ac.nz
Accepted for publication
5 April 2005

Background: Socioeconomic inequalities in child mortality are known to exist; however the trends in these inequalities have not been well examined. This study examines the trends in child mortality inequality between 1981 and 1999 against the background of the rapid and dramatic social and economic restructuring in New Zealand during this time period.

Methods: Record linkage studies of census and mortality records of all New Zealand children aged 0-14 years on census night 1981, 1986, 1991, 1996, each followed up for three years for mortality between ages 1-14 years. Socioeconomic position was measured using maternal education, household income, and highest occupational class in the household. Standardised mortality rates, rate ratios, and rates differences as well as regression based measures of inequality were calculated.

Results: Mortality in all socioeconomic groups fell between 1981 and 1999. Socioeconomic inequality in child mortality existed by all measures of socioeconomic position, however only trends by income suggested a change over time: the relative index of inequality increased from 1.5 in 1981-84 to 1.8 in 1996-99 ( $p$ trend 0.06), but absolute inequality remained stable (slope index of inequality 15/100 000 in 1981-84 and 14/100 000 in 1996-99.

Conclusions: Dramatic changes in income in New Zealand possibly translated into increasing relative inequality in child mortality by income, but not by education or occupational class. The a priori hypothesis that socioeconomic inequalities in child mortality would have increased in New Zealand during a period of rapid structural reform and widening income inequalities was only partly supported.

$\mathrm{T}$ he existence of socioeconomic inequalities in child mortality is confirmed by most studies. ${ }^{1-14}$ However, temporal trends in socioeconomic inequalities in child mortality remain largely unquantified. Some studies have suggested an increase in inequalities in all cause mortality over time, ${ }^{2}{ }^{15}$ one found a decline, ${ }^{16}$ and some found different trends by sex. ${ }^{817}$ Many of these studies have methodological problems. For example, being susceptible to the ecological fallacy, ${ }^{16}$ or to differential misclassification of socioeconomic position (SEP) over time because of use of area based measures of SEP, ${ }^{15}{ }^{17}$ failing to use methodology that adjusts for changing socioeconomic group size over time, ${ }^{218}$ or being susceptible to numerator-denominator bias. ${ }^{2}$

New Zealand is of particular interest in the context of trends in inequalities in child mortality. It underwent a significant period of economic and social restructuring through the 1980s and 1990s, similar to but more extensive than the (neo-liberal) changes that many other OECD countries experienced. ${ }^{19}{ }^{20}$ There is evidence that the distribution of social determinants of child health has changed over this period (see table 1). Despite these changes, child mortality has continued to fall, from 42/100 000 in 1980 to 24.6/100 000 in 2000 in 1-14 year olds (New Zealand Health Information Service), although it remains high by OECD standards. ${ }^{21}$ In contrast child health has deteriorated over this period by some measures, for example, there was an increase in avoidable hospital admissions and infectious disease admissions. ${ }^{22} 23$

There is reason to hypothesise that socioeconomic inequalities in child mortality may have increased over this time period. Socioeconomic inequalities in adult mortality in relative terms increased in most developed countries, including New Zealand, over the 1980s and 1990s. ${ }^{172829}$ If social and economic changes have an impact on inequalities in health, then it is plausible that inequalities in child mortality will respond more rapidly than inequalities in adult mortality. Why? Because there is less elapsed time in the life of a child for life course influences on health to have accumulated (putting aside intergenerational influences), perhaps increasing the ability to detect the recent impacts of changing socioeconomic conditions. Furthermore, the effects of health selection (that is, poor health causing a change in socioeconomic position, thereby inducing a (partly) spurious association of socioeconomic position and health) are largely removed as most child deaths are attributable to injury and the socioeconomic measures are based on parental characteristics.

However, the specific mechanisms by which macro level social and economic policy changes could translate into changing child mortality inequalities are not clear. Research suggests that political ideology (and therefore policy) is related to social inequalities and levels of health/mortality. ${ }^{30}$ Additionally there is increasing evidence of the detrimental effects of economic and social upheaval on adult and child health. ${ }^{31}{ }^{32}$ However, there are few, if any, studies that have tried to directly link policy changes at the macro level with changes in socioeconomic inequalities in child mortality at the individual level.

\section{METHODS}

The data in this study came from the New Zealand census mortality study. Four population cohorts were constructed by anonymously and probabilistically linking individual census and mortality records over four time periods from 1981 to 1996. ${ }^{33}$ The New Zealand Health Information Service provided mortality data for $0-14$ year olds for the periods 
Table 1 Changes to social determinants of child health over 1980s and 1990s in New Zealand

\begin{tabular}{|c|c|}
\hline Social determinant & Changes between 1981 and 1999 \\
\hline Average & $\begin{array}{l}\text { Mean equivalent household disposable incomes in households with children fell in real dollar terms over the } 1980 \text { s but } \\
\text { recovered slightly in the latter half of the 1990s. Households with dependent children had incomes less than } 90 \% \text { on } \\
\text { average over this time period. }{ }^{24}\end{array}$ \\
\hline Relative poverty & $\begin{array}{l}\text { In } 1987 / 8814.6 \% \text { of dependent children lived in households with an equivalised household income less than } 60 \% \text { of } \\
\text { median (net of housing costs). This increased to } 34.7 \% \text { in } 1991 / 92 \text { and declined to } 29.1 \% \text { in } 2000 / 01.25\end{array}$ \\
\hline Inequality & $\begin{array}{l}\text { The household equivalised disposable income Gini coefficient (across all New Zealand households, not just households } \\
\text { with children) increased from } 0.259 \text { in } 1982 \text { to } 0.322 \text { in } 1996^{26}\end{array}$ \\
\hline Education & $\begin{array}{l}\text { There has been a decline in the percentage of children with mothers with no formal qualifications (from } 47 \% \text { in } 1981 \text { to } \\
27 \% \text { in } 1996 \text { ) and a concomitant increase in the number of children with mothers with post-school qualifications over } \\
\text { this period. (New Zealand Census of Households and Dwellings). }\end{array}$ \\
\hline Occupational class/labour force status & $\begin{array}{l}\text { There has been redistribution of the labour force. Fewer children have parents in lower occupational classes ( } 49 \% \text { in } \\
1981 \text { and } 39 \% \text { in 1996) and more children have parents in upper occupational classes (New Zealand Census of } \\
\text { Households and Dwellings). There has also been an increase in the number of children with no parents in the labour } \\
\text { force from } 13.7 \% \text { of children in } 1986 \text { to } 23.4 \% \text { in } 1996 .^{27}\end{array}$ \\
\hline
\end{tabular}

1981-84, 1986-89, 1991-94, and 1996-99. Four cohorts were created, following up children aged $0-14$ years on census night for three years, with analysis being conducted on those deaths that occurred in children aged 1-14 years. (Note that this study is not well suited to the study of infant mortality as it is a closed cohort.)

The percentage of eligible mortality records linked ranged from $66 \%$ to $71 \%$, and the positive predictive value of the linkage was in excess of $96 \% .^{35}{ }^{36}$ Linkage varied by age, rurality, ethnicity, and small area deprivation, so linkage weights were applied to overcome any potential misclassification bias of mortality outcome caused by differential success of linkage. ${ }^{35}$ For example if 20 of 30 deaths in one cell were linked then the weights applied to those deaths that were linked was $30 / 20=1.5$. The weights were calculated in multiple small cells and then the non-linked census respondents were weighted down slightly to ensure that the total weighted number of children in the cohorts equalled the census night population.

To be included in the analysis children must have been at their usual residence on census night, which had to be a private dwelling. All family types were included in the analysis, however an adult over the age of 16, who was also in their usual residence, had to be present on census night. These restrictions resulted in the exclusion of $7 \%-9 \%$ of children in each cohort.
The "exposure", socioeconomic position, was measured at the household and parental level. Three different measures of socioeconomic position were used. When income was available on all adults in the house, it was collated and equivalised for household size using the New Zealand specific Jensen equivalisation index. ${ }^{38}$ Incomes on households with children were consumer price index adjusted to 1996 and then attached to each child in the household. All children were ranked based on income and then divided into three equal sized income groups, with cut points of low $(<\$ 20600)$, medium ( $\geqslant \$ 20600$ to $\leqslant \$ 33000)$, and high $(>\$ 33000)$ for calculation of the standardised rates.

Maternal education was classified using an intercensal classification of educational qualifications: no qualifications, school qualifications, and post-school qualifications. ${ }^{34}$ The determination of the child's mother was probabilistic, as family relationships within a household were not recorded in all censuses. This was performed by identifying the woman in the household who was between 15 and 45 years older than the oldest and youngest children. The variable was tested against the 1986 cohort, in which family relationships were identified, resulting in a sensitivity of $93 \%$, specificity of $71 \%$, and positive predictive value of $96 \%$.

The highest occupational class in the household was coded using the New Zealand specific Elley Irving occupational ranking. ${ }^{39}$

Table 2 Number of deaths, person time, and age and ethnicity standardised mortality rates 1-14 years both sexes for each socioeconomic variable, by cohort period

\begin{tabular}{|c|c|c|c|c|c|c|c|c|c|c|c|c|}
\hline & \multicolumn{3}{|c|}{ 1981-84 } & \multicolumn{3}{|c|}{$1986-89$} & \multicolumn{3}{|c|}{$1991-94$} & \multicolumn{3}{|c|}{$1996-99$} \\
\hline & Deaths & $\begin{array}{l}\text { Person } \\
\text { time }\end{array}$ & $\begin{array}{l}\text { Standardised } \\
\text { mortality rate }\end{array}$ & Deaths & $\begin{array}{l}\text { Person } \\
\text { time }\end{array}$ & $\begin{array}{l}\text { Standardised } \\
\text { mortality rate }\end{array}$ & Deaths & $\begin{array}{l}\text { Person } \\
\text { time }\end{array}$ & $\begin{array}{l}\text { Standardised } \\
\text { mortality rate }\end{array}$ & Deaths & $\begin{array}{l}\text { Person } \\
\text { time }\end{array}$ & $\begin{array}{l}\text { Standardised } \\
\text { mortality rate }\end{array}$ \\
\hline \multicolumn{13}{|l|}{ Income } \\
\hline Low & 225 & 525406 & 45.0 & 213 & 541747 & 41.8 & 201 & 620929 & 32.1 & 195 & 641673 & 29.4 \\
\hline Medium & 201 & 671669 & 33.6 & 171 & 631181 & 28.9 & 114 & 478969 & 24.2 & 123 & 515030 & 24.8 \\
\hline High & 186 & 610601 & 32.2 & 123 & 454993 & 30.3 & 108 & 536610 & 21.6 & 108 & 607858 & 18.9 \\
\hline \multirow[t]{2}{*}{ Missing } & 135 & 354562 & 37.3 & 144 & 362780 & 39.8 & 114 & 353627 & 31.6 & 111 & 335415 & 32.0 \\
\hline & 744 & 2162238 & & 648 & 1990701 & & 537 & 1990134 & & 537 & 2099976 & \\
\hline \multicolumn{13}{|l|}{ Education } \\
\hline Nil & 405 & 1028330 & 43.5 & 258 & 757143 & 36.3 & 207 & 609657 & 33.9 & 192 & 571622 & 32.5 \\
\hline School & 159 & 468725 & 38.6 & 144 & 514278 & 30.1 & 138 & 588858 & 24.0 & 162 & 740653 & 23.2 \\
\hline After school & 96 & 409042 & 22.6 & 180 & 558113 & 36.2 & 165 & 709063 & 22.9 & 153 & 700545 & 23.3 \\
\hline \multirow[t]{2}{*}{ Missing } & 87 & 256141 & 39.0 & 63 & 161167 & 41.8 & 24 & 82557 & 31.2 & 24 & 87156 & 21.6 \\
\hline & 744 & 2162238 & & 648 & 1990701 & & 537 & 1990134 & & 537 & 2099976 & \\
\hline \multicolumn{13}{|c|}{ Occupation class } \\
\hline Groups 4-6 & 357 & 952899 & 38.3 & 252 & 787,348 & 32.7 & 186 & 608228 & 30.6 & 177 & 644629 & 27.1 \\
\hline Groups 1-3 & 282 & 977424 & 33.1 & 294 & 966825 & 35.4 & 174 & 909691 & 19.3 & 201 & 1004247 & 22.2 \\
\hline \multirow[t]{2}{*}{ Non-active } & 105 & 231914 & 47.5 & 102 & 236528 & 43.0 & 177 & 472215 & 33.9 & 156 & 451100 & 29.2 \\
\hline & 744 & 2162238 & & 648 & 1990701 & & 537 & 1990134 & & 537 & 2099976 & \\
\hline
\end{tabular}

Mortality rate and person time per 100000. Deaths are weighted number of deaths. Number of deaths rounded to base 3 as per Statistics New Zealand confidentiality requirements. 


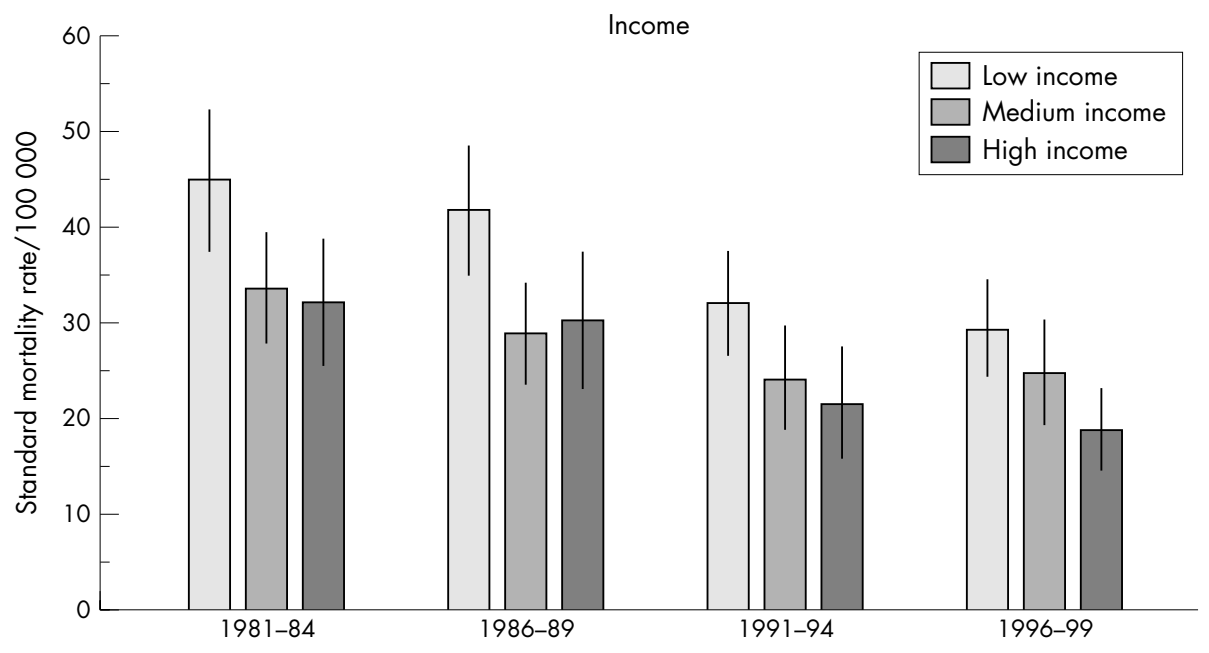

Figure 1 All cause standardised mortality rates of children aged 1-14 by income, education, and occupational class 1981-1999.
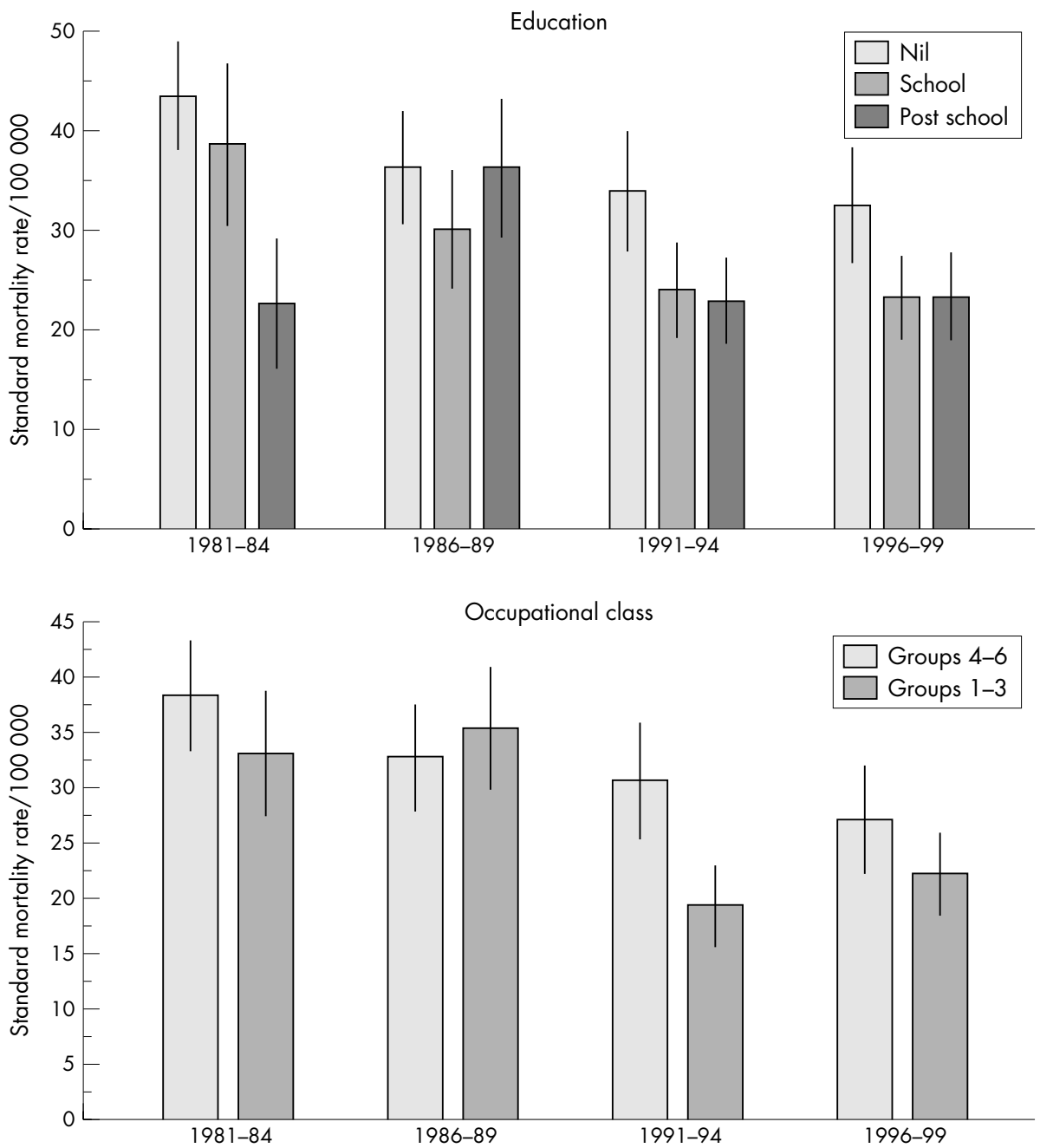

Standardised rates, rate ratios, rate differences, and 95\% confidence intervals were calculated across levels of the socioeconomic factors, ${ }^{40}$ using the age and ethnic group composition of the $1991 \mathrm{NZ}$ census population as the external standard. Results were standardised by ethnicity, as: ethnicity is a strong determinant of socioeconomic position; ethnicity is also a strong determinant of health independent of socioeconomic position; and the ethnic composition of
New Zealand children changed over this period. The number of children identified as Maori or Pacific increased by $20.7 \%$ and $45 \%$ respectively, compared with a $13 \%$ decline in nonMaori/non-Pacific children between 1981 and 1999. Results are presented for both sexes together to maximise statistical power and because it is not possible for sex to confound the relation between socioeconomic position and child mortality-that is, while sex predicts child mortality it is not 
Table 3 Changes in inequality in all cause mortality ages 1-14 both sexes, by cohort

\begin{tabular}{|c|c|c|c|c|c|}
\hline & & \multicolumn{2}{|l|}{ Relative } & \multicolumn{2}{|c|}{ Absolute (per 100000) } \\
\hline & & SRR $(95 \% \mathrm{Cl})$ & RII $(95 \% \mathrm{Cl})$ & SRD $(95 \% \mathrm{Cl})$ & SII $(95 \% \mathrm{Cl})$ \\
\hline Income & $\begin{array}{l}1981-84 \\
1986-89 \\
1991-94 \\
1996-99 \\
\mathrm{p} \text { (trend) }\end{array}$ & $\begin{array}{l}1.4(1.1 \text { to } 1.8) \\
1.4(1.0 \text { to } 1.8) \\
1.5(1.1 \text { to } 2.1) \\
1.6(1.2 \text { to } 2.1) \\
0.09\end{array}$ & $\begin{array}{l}1.5(1.0 \text { to } 2.2) \\
1.6(1.0 \text { to } 2.4) \\
1.8(1.1 \text { to } 3.0) \\
1.8(1.1 \text { to } 2.9) \\
0.06\end{array}$ & $\begin{array}{l}13(3 \text { to } 23) \\
12(1 \text { to } 22) \\
11(2 \text { to } 19) \\
11(4 \text { to } 17) \\
0.08\end{array}$ & $\begin{array}{l}15(1 \text { to } 29) \\
15(0 \text { to } 29) \\
15(3 \text { to } 28) \\
14(8 \text { to } 20) \\
0.12\end{array}$ \\
\hline Education & $\begin{array}{l}1981-84 \\
1986-89 \\
1991-94 \\
1996-99 \\
\mathrm{p} \text { (trend) }\end{array}$ & $\begin{array}{l}1.9(1.4 \text { to } 2.6) \\
1.0(0.8 \text { to } 1.3) \\
1.5(1.1 \text { to } 1.9) \\
1.4(1.1 \text { to } 1.8) \\
0.77\end{array}$ & $\begin{array}{l}2.2(1.5 \text { to } 3.4) \\
1.0(0.7 \text { to } 1.6) \\
2.0(1.3 \text { to } 3.0) \\
1.7(1.1 \text { to } 2.6) \\
0.89\end{array}$ & $\begin{array}{l}21(12 \text { to } 29) \\
0(-9 \text { to } 9) \\
11(4 \text { to } 18) \\
9(2 \text { to } 17) \\
0.62\end{array}$ & $\begin{array}{l}29(13 \text { to } 45) \\
1(-17 \text { to } 19) \\
17(6 \text { to } 28) \\
13(3 \text { to } 22) \\
0.57\end{array}$ \\
\hline Occupational class * & $\begin{array}{l}1981-84 \\
1986-89 \\
1991-94 \\
1996-99 \\
\mathrm{p} \text { (trend) }\end{array}$ & $\begin{array}{l}1.2(0.9 \text { to } 1.4) \\
0.9(0.7 \text { to } 1.1) \\
1.6(1.2 \text { to } 2.1) \\
1.2(0.9 \text { to } 1.6) \\
0.60\end{array}$ & $\begin{array}{l}1.7(1.2 \text { to } 2.6) \\
0.9(0.6 \text { to } 1.4) \\
2.4(1.3 \text { to } 4.4) \\
1.4(0.9 \text { to } 2.3) \\
0.99\end{array}$ & $\begin{array}{l}5(-2 \text { to } 13) \\
-3(-10 \text { to } 5) \\
11(5 \text { to } 18) \\
5(-1 \text { to } 11) \\
0.71\end{array}$ & $\begin{array}{l}19(1 \text { to } 36) \\
-2(-10 \text { to } 6) \\
20(1 \text { to } 38) \\
8(-3 \text { to } 19) \\
0.84\end{array}$ \\
\hline
\end{tabular}

SRR and SRD are for low/high for each variable, RIl and SIl include all children with the socioeconomic variable. *Occupational class comparisons are restricted to children with at least one adult in the household in the labour force.

associated with household measures of socioeconomic position.

To overcome the problem of changing socioeconomic group size over time, the relative and slope indices of inequality (RII and SII, respectively) were used to calculate population inequality in relative and absolute terms, respectively, in each cohort. ${ }^{41}$ The RII is equivalent to a relative risk measure for the poorest compared with the richest (or people with lowest compared with highest educational qualification or class), but uses mortality rates across all levels of income (and education or class) using regression. The SII is the absolute difference in mortality rates between the two extreme ends of the socioeconomic continuum. To increase the accuracy of the RIIs and SIIs we used five level groupings of income and education (that is, quintiles), and a four level grouping of occupational class, in the underlying regression models.

The programme of work of the New Zealand census mortality study has approval from the Wellington Ethics Committee (reference number 98/7).

\section{RESULTS}

Table 2 shows the number of deaths and person time in each cohort. Between 1981 and 1999 there was a change in the distribution of education and occupational class. Standardised mortality rates are shown in figure 1 and table 2. Mortality declined in all groups, but socioeconomic differences in child mortality existed during all cohorts and for all socioeconomic factors (except education and occupational class in 1986-89).

Mortality in all income groups declined from 1981-84 to 1996-99, although more in the high income group (41\%, p trend 0.03 ) than the middle $(26 \%$ p trend 0.08$)$ and low income groups $(35 \% \mathrm{p}$ trend 0.03 ). Trends in mortality inequality by income are seen in table 3 . These show an increase in the relative index of inequality from 1.5 to 1.8 between 1981-84 and 1996-99, which is of borderline significance ( $p$ trend 0.06). There is also overlap of the confidence intervals of these values. There was little, if any change, in absolute inequality over time as measured by the slope index of inequality.

Mortality rates declined in the no qualification and school qualification groups, but showed some variation in the postschool qualification group (possibly because of the small numbers of children in this group in the earlier cohorts). The effect measures show the presence of both relative and absolute inequality in child mortality in all cohorts, except 1986-89, but there is no clear trend over time.

\section{What is already known?}

- Socioeconomic inequalities in child mortality exist in many countries for most causes of death.

- There is increasing evidence that in developed countries adult socioeconomic inequalities are increasing, but trends over time in child inequalities remain unclear.

- New Zealand has experienced significant social and economic upheaval over the 1980s and 1990s, which directly affected the social determinants of child health, particularly household income.

- Overall child mortality rates fell during the 1980s and 1990s in New Zealand, but trends in socioeconomic inequalities in child mortality are unknown.

The occupational class groups also each showed a decline in mortality. There was weaker evidence of mortality gradients within occupational class and the $95 \%$ confidence interval of the rate ratio only excluded 1.0 in 1991-94. However the RII and SII, which take into account the changing group size and use a greater number of groups, are more suggestive of mortality gradients by occupational class. There was no clear trend in mortality inequality by occupational class over time.

\section{DISCUSSION}

Mortality rates decreased for children in all socioeconomic groups between 1981-84 and 1996-99. However, socioeconomic gradients in mortality were present in most cohorts and by most measures of socioeconomic position. These results are suggestive (but not incontrovertibly) of an increase in relative (but not absolute) child mortality differences by income in New Zealand between 1981-84 and 1996-99. However, by maternal education and parental occupational class there was no clear trend in socioeconomic inequalities in child mortality.

A strength of this study, in relation to previous studies looking at trends in child mortality, is the use of direct measurement of a child's socioeconomic position by individual and household census data-not the reliance on neighbourhood or ecological measures of socioeconomic position. Only one other study of child mortality inequalities 


\section{What this study adds}

- Relative inequalities in child mortality by income increased from 1981-84 to 1996-99, although the change was of borderline statistical significance. Conversely, absolute inequalities were stable or even decreasing slightly over time.

- Inequalities in child mortality by maternal education and highest occupational class of the household were unstable over the 1980s and 1990s, with no clear trend.

- Reasons why relative inequalities in child mortality may have increased only by income include: income being the dominant axis of increasing socioeconomic inequalities for children; a shorter time lag between income and mortality risk as compared with class and maternal education; better measurement of income as compared with class and education.

- The diversity of trends by the different measures of socioeconomic position suggests that no one measure should be used in isolation when studying time trends.

- The theoretical and physical links between policy changes and changes in child mortality inequalities need to be explored further.

has access to such individual or household level data, and that compared much earlier time periods in Sweden (1961-66 with 1981-86). ${ }^{8}$ Secondly, the four cohorts used in the comparisons over time were essentially identical with regard to study design. Thirdly, we adjusted for the changing distribution of socioeconomic factors over time using the relative and slope indices of inequality.

Despite using an entire population study sample there were not many deaths in this age range (744 in the 1981-84 cohort, 648, 537, and 537 respectively in the subsequent cohorts). The small number of deaths led to wide confidence intervals around the effect measures, making the interpretation of trends more difficult. The small number of deaths in the cohorts also precluded analysis of trends by subgroup (for example, by ethnicity). This is unfortunate, as there is evidence that the social and economic reforms experienced were differential in their impact on ethnic groupings of children. For example, income declined more in Maori families compared with non-Maori. ${ }^{24}$ Analyses by specific cause of death will be presented in another paper, however the overall trends presented in this paper are similar to those for unintentional injury deaths- the most common cause of death.

Our analyses are based on weighted numbers of deaths to adjust for any linkage bias during the formation of the cohorts. Workings presented elsewhere for adult mortality suggest these weights work well. ${ }^{35}$ To further ensure that these weights worked for children we performed checks and made adjustments specific for causes of child mortality,

\section{Policy implications}

Policy makers need to consider inequalities in child mortality, not just adult mortality, when designing and implementing policies that have an impact on the socioeconomic determinants of health-particularly income distribution. hence we are confident the results presented in this paper for children are not substantially distorted by linkage bias.

The decline in child mortality in all socioeconomic groups between 1981 and 1984 and 1996 to 1999 despite the (largely unfavourable) changes to social determinants of health illustrates that there are other determinants and/or buffers of child mortality. For example, while injury mortality rates fell between 1981 and 1999, this was not mirrored in hospitalisation rates, which may have increased slightly. ${ }^{42} 43$ This paradox may reflect improvements in trauma care of children-that is, the health system acting as a barrier between risk factors for injury (which may include social determinants) and mortality outcome. There is some international evidence suggesting that healthcare systems can partially ameliorate the effect of social inequalities, at least for infant mortality. ${ }^{44}$ Societal changes resulting in decreased exposure to "risk" activities, such as fewer children cycling or walking to school, may also influence mortality. In addition public health interventions, such as immunisation and injury prevention, may also contribute to declining child mortality.

This study has shown evidence that despite these secular falls in mortality, socioeconomic disparities exist at all points in time by education, income, and (less convincingly) occupational class. The lack of consistency in trends by these socioeconomic variables is perhaps surprising. However, there are a number of theoretical and practical reasons that might explain why an increase in inequalities in child mortality was only seen by income, even if it was a more modest effect than might have been anticipated and only for relative inequalities. From a theoretical perspective changes in child mortality inequalities might be expected to centre on income if income was the major axis of change of inequality. Table 1 illustrates the pronounced deterioration in all domains of income over this time period, although whether it was the primary axis of inequality is debatable. In addition social and economic change may result in a more immediate alteration in income in comparison with educational status, which is fixed earlier in life. Finally for pragmatic reasons income may be a more consistent measure of socioeconomic position over the time period studied, as it was more stable in social meaning and comparable because of consumer price index adjustment as well as having more levels across which to assess inequality.

Regarding the lack of temporal changes in child mortality inequality seen by maternal education, it is possible that the methods used to create the maternal education variable in this study introduced misclassification that obscured any trends over time. However, using a "dominant" approach to education (that is, highest in the house) the same findings were noted (data not presented). A possible explanation for the inconsistent findings lies in the dramatic reshuffle of the education system in the past 20 years in New Zealand, which has resulted in a large increase in school and post-school qualifications in younger age groups, whose children are in this study. It is possible that the increasing homogeneity of educational qualifications over the time period studied means that this is a less discerning measure of inequality than income. Although there is some evidence to suggest that, at least in Norway for infant mortality, mothers with no formal qualifications are a more marginalised group than previously, resulting in an increase in relative inequality. ${ }^{45}$

With regards to the findings by occupational class there are a number of important points to highlight. Firstly, occupational class appears to be less important than labour force status as a determinant of child mortality in New Zealand. This is supported by the higher mortality rates seen in the non-labour force group and the weak evidence of occupational class gradients (the $95 \%$ confidence intervals included 1 in all cohorts except 1991-94). The linked nature of these 
data allows us to establish that the non-labour force group in this study consists largely of children who live in single parent households, where no parent was active in the labour force (at least as it is formally defined). Previous analyses of NZCMS data have shown that this excess mortality in single parent households is attributable to low income, rather than the nature of the household. ${ }^{1}$ Given the increase in the number of single parent households over time this has important implications for policy makers.

Secondly, the increasing number of children with parents in this non-active group means that the trends by occupational class are inherently inaccurate. This study shows an almost doubling in the proportionate size of this non-labour force group between 1981-84 and 1996-99, and measures of trends in inequality by occupational class only use data from children within the occupational group. In adults exclusion of the economically inactive is estimated to underestimate the social class gradient by $25 \%$ for men and $60 \%$ for women. ${ }^{46}$ The exclusion of this group of children with the highest risk of mortality and the progressive increase in the size of this group would suggest that occupational class might not be an appropriate variable to be monitoring temporal trends in socioeconomic inequalities in child mortality in a population.

In theory, selection of a measure of socioeconomic position should be based on prior conceptualisation of the pathways between socioeconomic position and the health outcome of interest. ${ }^{47}$ Although pragmatism often prevails in selection of a measure of socioeconomic position, the differing trends and inherent problems within each measure of socioeconomic position in this study suggest that to adequately monitor socioeconomic inequalities in child mortality, measurement of multiple dimensions of socioeconomic position is required.

Considering the increase in relative inequalities in mortality by income, there are innumerable pathways by which changes in social determinants in child mortality may have acted. For example, it is possible that decreases in absolute income could place children in injury promoting environments (that is, unsafe cars, unfenced section, and unsupervised playing on streets). However, while specific pathways offer explanations, socioeconomic gradients occur in multiple causes of child mortality. ${ }^{6}$ Explanations of changes in inequalities in mortality must both encompass the underlying universal process and the micro-level pathways to each of these diverse causes of death and ill health. This explanation and theory is where ongoing efforts need to be focused.

\section{SUMMARY STATISTICS NEW ZEALAND SECURITY STATEMENT}

The New Zealand census mortality Study (NZCMS) is a study of the relation between socioeconomic factors and mortality in New Zealand, based on the integration of anonymised population census data from Statistics New Zealand and mortality data from the New Zealand Health Information Service. The project was approved by Statistics New Zealand as a Data Laboratory project under the Microdata Access Protocols in 1997. The datasets created by the integration process are covered by the Statistics Act and can be used for statistical purposes only. Only approved researchers who have signed Statistics New Zealand's declaration of secrecy can access the integrated data in the Data Laboratory. (A full security statement is in a technical report at http://www.wnmeds.ac.nz/nzcms-info.html.) For further information about confidentiality matters in regard to this study please contact Statistics New Zealand.

\section{Authors' affiliations}

C Shaw, T Blakely, J Atkinson, P Crampton, Department of Public Health, Wellington School of Medicine and Health Sciences, University of Otago, Wellington, New Zealand
Funding: Caroline Shaw acknowledges salary support from the Australasian Faculty of Public Health Medicine during the course of this research. The New Zealand census-mortality study was initially funded by the Health Research Council of New Zealand. The Ministry of Health New Zealand is now the primary funding agency for this study.

Competing interests: none.

Ethical approval: the programme of work of the New Zealand census mortality study has approval from the Wellington Ethics Committee (reference number 98/7).

\section{REFERENCES}

1 Blakely T, Atkinson J, Kiro C, et al. Child mortality, socioeconomic position, and one-parent families: independent associations and variation by age and cause of death. Int J Epidemiol 2003;32:410-18

2 Botting B. Mortality in childhood. In: Drever F, Whitehead M, eds. Health inequalities. London: The Stationery Office, 1997:83-94.

3 Gissler M, Rahkonen O, Jarvelin MR, et al. Social class differences in health until the age of seven years among the Finnish 1987 birth cohort. Soc Sci Med 1998;46:1543-52.

4 Judge $K$, Benzeval M. Health inequalities: new concerns about the children of single mothers. BMJ 1993;306:677-80.

5 Nersesian WS, Petit MR, Shaper R, et al. Childhood death and poverty: a study of all childhood deaths in Maine, 1976 to 1980 . Pediatrics 1985;75:41-50.

6 Nelson MD Jr. Socioeconomic status and childhood mortality in North Carolina. Am J Public Health 1992;82:1131-3.

7 Mare RD. Socioeconomic effects on child mortality in the United States. Am J Public Health 1982;72:539-47.

8 Ostberg V. Social class differences in child mortality, Sweden 1981-1986. J Epidemiol Community Health 1992;46:480-4.

9 Pensola TH, Valkonen T. Mortality differences by parental social class from childhood to adulthood. J Epidemiol Community Health 2000;54:525-9.

10 Schuman J. Childhood, infant and perinatal mortality, 1996; social and biological factors in deaths of children aged under 3. Popul Trends 1998;92:5-14

11 Vagero D, Ostberg V. Mortality among children and young persons in Sweden in relation to childhood socioeconomic group. J Epidemiol Community Health 1989;43:280-4.

12 West P. Inequalities? Social class differentials in health in British youth. Soc Sci Med 1988;7:291-6.

13 West P. Health inequalities in the early years: is there equalisation in youth? Soc Sci Med 1997;44:833-58.

14 Singh GK, Yu SM. US childhood mortality, 1950 through 1993: trends and socioeconomic differentials. Am J Public Health 1996;86:505-12.

15 Diliberti JH. The relationship between social stratification and all-cause mortality among children in the United States: 1968-1992. Pediatrics 2000; 105:e2.

16 Bremberg S. Does an increase of low income families affect child health inequalities? A Swedish case study. J Epidemiol Community Health 2003;57:584-8.

17 Turrell G, Mathers C. Socioeconomic inequalities in all-cause and specificcause mortality in Australia: 1985-1987 and 1995-1997. Int J Epidemiol 2001;30:231-9.

18 Ostberg V, Vagero D. Socio-economic differences in mortality among children. Do they persist into adulthood? Soc Sci Med 1991;32:403-10.

19 Boston J, Dalziel P, St John Se. Redesigning the Welfare State in New Zealand. Auckland: Oxford University Press, 1999.

20 Navarro V. Neoliberalism, "globalization," unemployment, inequalities, and the welfare state. Int J Health Serv 1998;28:607-82.

21 Ministry of Health. Our children's health: key findings on the health of New Zealand children. Wellington: Ministry of Health, 1998.

22 Dharmalingam A, Pool I, Baxendine S, et al. Trends and patterns of avoidable hospitalisations in New Zealand: 1980-1997. N Z Med J 2004;1 17:976-96.

23 Mills CF, Tobias M, Baker M. A re-appraisal of the burden of infectious disease in New Zealand: aggregate estimates of morbidity and mortality. N Z Med J 2002;115:254-7.

24 Mowbray M. Distributions and disparity: New Zealand household incomes. Wellington: Ministry of Social Policy, 2001.

25 Ministry of Social Development. The social report. Wellington: Ministry of Social Development, 2003.

26 Statistics New Zealand. Incomes. New Zealand Now. Wellington: Statistics New Zealand, 1999.

27 Statistics New Zealand. Children. New Zealand Now. Wellington: Statistics New Zealand, 1999.

28 Mackenbach JP, Bos V, Andersen O, et al. Widening socioeconomic inequalities in mortality in six Western European countries. Int J Epidemiol 2003;32:830-7.

29 Blakely $T$, Tobias $M$, Robson B, et al. Widening ethnic mortality disparities in New Zealand 1981-99, and variable life expectancy trends 1950-2002. Soc Sci Med (in press).

30 Navarro V, Shi L. The political context of social inequalities and health. Soc Sci Med 2001;52:481-91.

31 Men T, Brennan P, Boffetta P, et al. Russian mortality trends for 1991-2001: analysis by cause and region. BMJ 2003;327:964.

32 Tangcharoensathien V, Harnvoravongchai $P$, Pitayarangsarit $S$, et al. Health impacts of rapid economic changes in Thailand. Soc Sci Med 2000;51:789-807. 
33 Blakely T, Salmond C, Woodward A. Anonymous linkage of New Zealand mortality and census data. Aust N Z J Public Health 2000;24:92-5.

34 Hill S, Atkinson J, Blakely T. Anonymous record linkage of census and mortality records: 1981, 1986, 1991, 1996 census cohorts. NZCMS technical report no 3. Public Health Monograph Series. Wellington: Department of Public Health, Wellington School of Medicine and Health Sciences, 2002

35 Fawcett J, Blakely T, Atkinson J. Weighting the 81, 86, 91 and 96 censusmortality cohorts to adjust for linkage bias. NZCMS technical report no 5 . Public Health Monograph Series. Wellington: Department of Public Health, Wellington School of Medicine and Health Sciences, 2002.

36 Blakely T, Salmond C. Probabilistic record linkage and a method to calculate the positive predictive value. Int J Epidemiol 2002;31:1246-52.

37 Reference withdrawn.

38 Blakely T. The New Zealand census-mortality study: socioeconomic inequalities and adult mortality 1991-94. Wellington: Ministry of Health, 2002.

39 Elley W, Irving J. Revised socio-economic index for New Zealand. New Zealand Journal of Educational Studies 1976;11:25-31.

40 Rothman KJ, Greenland S. Modern epidemiology. 2nd ed. Philadelphia: Lippincott-Raven, 1998.
41 Mackenbach JP, Kunst AE. Measuring the magnitude of socio-economic inequalities in health: an overview of available measures illustrated with two examples from Europe. Soc Sci Med 1997;44:757-71.

42 D'Souza A, Wood E. Making New Zealand fit for children. Promoting a national plan of action for New Zealand children (healthy lives section). Wellington: Unicef, 2003.

43 Ministry of Health. Our health, our future: the health of New Zealanders 1999. Wellington: Ministry of Health, 1999.

44 Macinko JA, Shi L, Starfield B. Wage inequality, the health system, and infant mortality in wealthy industrialized countries, 1970-1996. Soc Sci Med 2004;58:279-92.

45 Arntzen A, Moum T, Magnus P, et al. The association between maternal education and postneonatal mortality. Trends in Norway, 1968-1991. Int J Epidemiol 1996;25:578-84.

46 Martikainen P, Valkonen T. Bias related to the exclusion of the economically inactive in studies on social class differences in mortality. Int J Epidemiol 1999;28:899-904.

47 Lynch J, Kaplan GA. Socioeconomic position. In: Berkman L, Kawachi I, eds. Social epidemiology. New York: Oxford University Press, 2000.

\section{APHORISM OF THE MONTH}

\section{There is no defence against kindness (Samuel Levin)}

ow many times have you found that the way to deal with someone who is being particularly difficult in achieving a public health objective is by a concerted effort of being reasonable and keeping the agenda on an adult level? 